\title{
Bailando con la destrucción: Sobre cultura común y música popular en la Transición Española (1977-1987)
}

\section{Antonio Méndez Rubio \\ UNIVERSITAT DE VALÈNCIA·Antonio.Mendez@uv.es}

Profesor del departamento de Teoría de los Lenguajes de la Universitat de València. Ha publicado varios ensayos de crítica cultural, como Encrucijadas: Elementos de crítica de la cultura (1997) o La desaparición del exterior: Cultura, crisis y fascismo de baja intensidad (2012), así como estudios sobre poética y sociedad: Poesía y utopía (1999), Poesía sin mundo: Escritos sobre poética y sociedad (2004). A su vez, ha publicado diversos poemarios, como El fin del mundo (1995, Finalista del X Premio de Poesía Hiperión), Trasluz (2002), Razón de más (2008) o Siempre y cuando (2011).

RECIBIDO: 4 DE FEBRERO DE 2013

ACEPTADO: 10 DE ABRIL DE 2013

Resumen: El artículo analiza desde una perspectiva crítica el legado musical de los años de la llamada Transición, poniendo el foco en las relaciones entre música y sociedad que tan poca consideración han tenido desde la crítica musical y la musicología, áreas desde las que se han realizado aproximaciones partiendo de una visión de la música como un ámbito estético autónomo más que como una práctica social. El artículo pone el acento en los espacios de conflicto generados por las prácticas musicales de la época y en las estrategias de borramiento de ese conflicto con las que se ha tratado de abordar, en los últimos años, el periodo y su escena musical.

Palabras Clave: Transición Española, música, sociedad, práctica social.

Abstract: This article analyzes the musical legacy of the Spanish Transition to democracy from a critical perspective. Musical criticism and Musicology have studied music as an autonomous aesthetic field, instead of a social praxis. Remarkably, the academic world has not paid much attention to the relationship between music and society. This article stresses out the space of conflict generated by musical experiences during that period of time and the strategies that have been applied over the past few decades in what we consider to be an attempt to erase it.

Key Words: Spanish Transition to Democracy, music, society, social practice. 


\section{nunca fue bella la derrota así como alguien la quiere pintar \\ Sabino MÉNDEZ}

\section{La producción de desmemoria histórica}

En toda memoria puede que haya, en silencio, un resto inextinguible de olvido. Pensar en eso no ayuda a darle voz, ni tampoco contribuye siquiera a reconocerlo. Por otra parte, cuando el imaginario colectivo, por una u otra razón, inicia una secuencia de giros en el discurso público para al menos delimitar o mantener en su sitio ese núcleo de fuerza, entonces lo previsible es que se levante en el aire una espiral de ruido. Ese rumor señala su propio vacío, a la vez que, fugazmente, libera del paso del tiempo la imposibilidad de decir algo, de mencionar de nuevo lo no-dicho. Los actuales debates sobre la necesidad e incluso la necesaria legalidad de la memoria histórica pueden ser una muestra de esto mismo: se hace un esfuerzo considerable por abrir espacios para el recuerdo compartido, cuya visibilidad aplaza el pulso de lo que en el recuerdo es solo olvido, fondo de negación.

En esta encrucijada, hay un conocido pasaje de Walter Benjamin en sus Tesis de filosofía de la historia que debería ser recordado aquí:

Articular históricamente lo pasado no significa conocerlo "tal y como verdaderamente ha sido". Significa adueñarse de un recuerdo tal y como relumbra en el instante de un peligro. (...) El peligro amenaza tanto al patrimonio de la tradición como a los que lo reciben. (...) En toda época ha de intentarse arrancar la tradición al respectivo conformismo que está a punto de subyugarla (Benjamin, 1990: 180).

El período de la llamada Transición Española (1977-1987), donde a su vez retorna como nunca lo dicho y lo borrado a propósito de la Guerra Civil (1936-1939), es por definición un momento de peligro, en términos benjaminianos, que la cultura oficial y la opinión pública solo pueden recuperar situándolo en una clave (naturalizada por inercial) de conformismo subyugante. En el punto en que la memoria se produce como nostalgia ocurre, entre otras cosas, lo que no debería: la misma complacencia celebratoria, por contraste con la precariedad de la vida común, sintomatiza la latencia de una deuda, de una herida aún abierta, de un deseo y de una cuenta pendiente, que todavía está mirando hacia el futuro.

Entre la avalancha de textos y contenidos mediáticos que buscan masivamente recordar los años de paso del franquismo a la democracia en España, implican una especial y seductora opacidad aquellos que incorporan la necesidad de convocar una cierta memoria musical de la sociedad española. Dos películas del mismo año 2005 podrían ser un ejemplo de algunas de las heridas y las suturas que esa memoria plantea. Estoy refiriéndome a El Calentito, de Chus Gutiérrez (2005), y a Los dos lados de la cama, de 
Emilio Martínez-Lázaro (2005). Ambos films señalan un momento y un espacio de crisis de subjetividad y de socialidad, así como una forma de afrontar esa crisis, de forma que emergen entre los dos casos convergencias y divergencias no exentas de valor hermenéutico y explicativo.

En ambos la historia asume, de entrada, la crisis de la linealidad narrativa en virtud de la inserción de clips musicales que secuencian el ritmo en la resolución de la intriga, al tiempo que horadan la diégesis hacia un ámbito de suspensión de la experiencia (del tiempo). En El Calentito la crisis del mundo se manifiesta ante todo en la conmoción de la autoridad en el modelo de pareja y de familia tradicional -donde a su vez cobra un claro protagonismo el conflicto entre generaciones, entre jóvenes y adultos. Esa crisis se ve acompañada e intensificada por el deterioro del marco político colectivo: un Estado marcado por la asfixia social, la corrupción policial y el desprecio clandestino pero muy generalizado hacia la dictadura. La acción se sitúa en 1981, y su desenlace queda supeditado a la tensión histórica que supuso el intento de golpe de estado del 23 de febrero de ese año. El 23-F funciona así como catalizador del peligro, como epicentro de la inseguridad social y personal: es como si toda la ilusión y todo el conflicto se concentraran en esa fecha, y como si esa fecha reivindicara su materialidad, su desafío como real, mediante el montaje alterno con imágenes documentales y el recurso a canciones de la época en la banda sonora. Entre éstas sobresale la cita casi hímnica de Parálisis Permanente ("Quiero ser santa"), que ayuda a reforzar la opción por el punk del grupo de chicas protagonistas, cuyo nombre de guerra será Las Siux. De esta forma, la película de Gutiérrez intenta resistir al borrado del lugar de las mujeres en la Historia, y para ello sitúa la acción de la protagonista (Sara) en un espacio donde ese borrado se ha reproducido de una forma privilegiada: en la historia cultural y, más en concreto, en la historia de la música popular. En efecto, en pocos lugares como en la historia de la música popular contemporánea se ha dado de una forma más eficaz la premisa divisoria entre la potencia activa, expresiva, de la masculinidad y la experiencia pasivizada y reprimida de la feminidad. En este sentido, "la performance del rock masculino, pues, convierte a la mujer en un objeto silencioso de intercambio entre hombres" (Bradby, 1990: 345).

Pero la resistencia crítica al borrado de la experiencia femenina, en El Calentito, se representaría de una forma mutilada si no se atiende a cómo esa crítica está asociada en la película a una nueva crisis: la de la identidad de género, que en última instancia repercute en una crisis de identidad pura y dura. El guion subraya la centralidad del personaje travestido, cuya ambigüedad sin solución afecta de raíz a su propio nombre: Antonia/o -el nombre castizo, sinécdoque de lo español por excelencia. El personaje de Antonia es presentado nada menos que como una "terrorista del género", en cuya figura se condensan y agudizan las tensiones políticas y existenciales del momento social -como cuando Antonia 
declara desafiante que "lo nuestro sí que es una transición". Además, es el personaje cuya valentía desobstruye el nudo del suspense y reabre la circulación del flujo narrativo y vital. Ese fluir de libertad y autonomía queda emblematizado por la secuencia de la carrera de Sara, entre el miedo y la rabia, hacia el concierto nocturno de Las Siux en pleno golpe de estado. El instante en que se hace máxima la presión neofascista es el instante en que el diálogo asume su decisión combativa: “-¿Dónde está la lucha? -En el escenario." Así pues, la celebración final no anula el conflicto inscrito en la decisión de la autonomía, ni el mal rollo por la ruptura de vínculos que esa decisión conlleva, sino que hace de ese conflicto el motor de una lucha que la última secuencia escenifica de un modo convulso y festivo.

Por su parte, Los dos lados de la cama está concebida como una especie de segunda parte de El otro lado de la cama (2002), dirigida también por Emilio Martínez-Lázaro y que fuera un notable éxito de taquilla, con cifras que alcanzaron los tres millones de espectadores en salas de cine. Situada en las coordenadas de la actualidad, y protagonizada por un juego de parejas y amigos treintañeros de clase media, Los dos lados de la cama convoca el período de los años ochenta a través del trabajo de adaptación de Roque Baños con un repertorio selecto de canciones populares de aquellos años (Alaska, Loquillo, Los Secretos, Mecano...) decisivos para la formación personal de los protagonistas (y para la configuración del marco colectivo en que transcurren sus vidas). La primera escena arranca ya con una adaptación a tiempo lento del hit de Alaska y Pegamoides "Bailando", aquí traducido al contoneo seductor sobre el piano de Raquel, cuya mirada a cámara emplaza el deseo escópico en la mirada masculina de Javier y Pedro, pero también femenina de Marta (prometida de Javier), que los acompaña desde su mesa entre el público y que pronto sabremos que es la amante secreta de Raquel (novia de Pedro). El descubrimiento de esta infidelidad lésbica dispara los efectos cómicos en la película y rememora el clima de libertades sexuales heredado justamente de los años de la transición española.

Sin embargo, las referencias al mundo colectivo y social están relegadas ahora a las apariciones estrambóticas y los despropósitos gramaticales de Rafa, el amigo taxista, currante de estilo cutre, abandonado por Pilar, a quien se debe la presentación distanciada e irónica de las dos "parejas de moda", así como la jocosa exhortación: “¡Alegría, que estamos en España!". El personaje de Rafa, desde el principio hasta el final (cuando se lamente, visto lo visto, de que "Esto se va al garete. España se acaba"), es el encargado del trabajo sucio, el de contextualizar la acción -en un guiño hacia la estética de Pedro Almodóvar pasada por Santiago Segura- en el terreno vergonzoso de la España negra: el país del tradicionalismo machista, la violencia doméstica y la incultura. También Rafa es el responsable de ensanchar el marco crítico de la historia: si en un primer círculo la historia emblematiza la crisis del compromiso de pareja y de identidad de género (a partir del leitmotiv de El otro lado de la cama. "Hay estudios que dicen que todos somos 
bisexuales"), en un segundo círculo concéntrico, más ancho que el primero, la crisis se proyecta hacia una crisis de confianza, una crisis de los vínculos de amistad y sociales en sentido amplio -su chica deja a Rafa por Carlos, su mejor amigo y "la única persona en la que puedo confiar"... El vaciamiento de sentido del compromiso (de pareja) lleva implícito un deterioro irreversible de los vínculos matrimoniales y familiares más tradicionales, pero afecta incluso a una cierta devastación de la confianza como medio de cohesión relacional y social. Así, el clima de complicidad y de sonrisa que la película propone no puede separarse de un trasfondo un tanto más amargo: la apelación a un mundo individualista y desorientado, en el que, como ha escrito Z. Bauman, "dependencia ha llegado a ser una palabrota: se refiere a algo de lo que las personas decentes deberían avergonzarse" (2001: $88)$.

En contraste con El Calentito, Martínez-Lázaro proyecta un punto de vista masculino en crisis, donde los hombres están abiertamente en manos de las mujeres y las decisiones masculinas se plantean continuamente en clave autoparódica. En esa divertida caída en desgracia irrumpe casi anónimamente una nueva mujer que catalizará la crisis de Javier y Pedro ofreciendo la posibilidad de una nueva vía: el sexo en trío. A ella se le debe entonces una reflexión iluminadora en pleno abandono depresivo de los dos amigos: "A mí hablar no me gusta mucho. Yo tengo un remedio mejor: bailar". El nuevo y feliz trío acude a una academia de baile para curar sus males más inmediatos. El baile, en ese punto, es obviamente un señuelo para la seducción y la posibilidad de un nuevo éxito sexual, a la vez que se convierte, no menos obviamente, en un sustituto de lo que falta: no solo las respectivas parejas, Marta y Raquel, sino la comunicación que permitiría recuperarlas o construir unos vínculos relacionales nuevos. La comunicación, como precondición no solo de la pareja sino de la vida en común, se presenta amablemente como un lugar desértico, intempestivo -“a mí no me gusta hablar mucho...”. El baile se presenta así como un epítome del fracaso, de la derrota personal y social. No en vano, la banda sonora incluye ahora temas de finales de los ochenta (Los Ronaldos, Los Rodríguez), haciendo posible una lectura política de la película en clave de desencanto, de cínica resaca post-transición.

En Los dos lados de la cama el baile en los números musicales es, de hecho, el momento reservado para la acción coral, en la línea de idealización armónica de la comunidad propia del musical clásico de Hollywood. Las letras de las canciones y los movimientos corporales en la danza instauran una dialéctica autorreflexiva, que simpatiza no obstante con la nostalgia más conservadora, también en la línea del musical cinematográfico tardío. El musical de éxito masivo propio de los años ochenta, tal como se aprecia en Flashdance (A. Lyne, 1983) o Dirty Dancing (E. Ardoline, 1987), representa de hecho un intento de pacto entre el revisionismo ácido de los setenta y el modelo clásico de identificación subyugante, y hace esto en virtud de una historia aurática de aprendizaje 
individual y de pareja -por cierto, cada vez más cercana a la sensibilidad gay (Feuer 1992:166). ¿Deconstrucción o pastiche? Tal vez a medio camino, las dos películas de Martínez-Lázaro, vistas desde la óptica del repertorio musical, parecen dar la razón a Jane Feuer:

En lugar de un proceso de creación y preterición, lo que en realidad tenemos aquí en un sentido histórico es un proceso de cita y preterición, ya que nada enteramente nuevo es realmente creado nunca. A lo largo del tiempo, la síntesis de formas del espectáculo pasadas y presentes elimina la distinción entre unas y otras formas, de manera que el musical aparece al mismo tiempo como innovador y tradicional. Así, el espectáculo se da en un perpetuo presente, que es también un pasado perpetuo (1992: 115).

En una especie de apoteosis delirante y postmoderna, la negación de la temporalidad

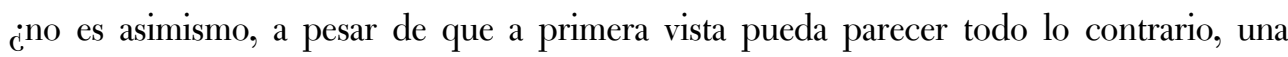
negación de la memoria? Poniendo un símil, sería como hacer la pregunta de si la práctica del remember en las macrodiscotecas es paradójicamente una celebración colectiva de la desmemoria, una catarsis del dolor que causa el olvido. Al fin y al cabo, como sabía Barthes, "sin olvido no hay vida posible" (1993: 51).

En resumen, si se comparara El Calentito con Los dos lados de la cama se encontraría algo más que una proximidad temática (la historia sexual y musical de la juventud en la España reciente) y una pasmosa coincidencia en el papel de Sara/Marta, interpretado por la misma Verónica Sánchez, joven actriz catapultada al reconocimiento masivo gracias a su papel de hija ejemplar en la telecomedia Los Serrano (Tele 5), que narra las peripecias de una familia numerosa y bien avenida. Hay entre los dos textos filmicos, sin embargo, una doble diferencia que podría resolverse en una nueva convergencia interpretativa: la primera pone en escena una historia de aprendizaje sexual y político; la segunda propone una comedia basada en el motivo de la desorientación sexual y social (donde la desaparición de lo político solo es comparable a la desaparición de las drogas); la primera maneja un punto de vista femenino y constructivo mientras la segunda juega la baza de un punto de vista masculino que se autodesmonta... Si se pudiera juzgar así, desde un punto de vista histórico, ¿cuál de las dos tendría razón? ¿Qué tipo de (des)memoria produce cada una de las películas? ${ }_{\mathrm{C}} \mathrm{O}$ acaso se complementan, como si tuvieran una misma raíz, y las dos pudieran ser verdad, en el sentido de haber leído la historia común como un episodio de relativa autonomía para la mujer, de desorientación y despolitización masculinas, y así sucesivamente?

En el supuesto de que pudiéramos leer las dos películas en una secuencia temporal, como de hecho permiten las referencias culturales de ambas, tendríamos entonces, además, una relación protosecuencial entre ellas: como si de este modo El Calentito tuviera lugar 
primero (primeros ochenta) y Los dos lados de la cama después (en el no-tiempo de los últimos ochenta y primeros noventa). Si así fuera, ¿no nos toparíamos entonces con el paso de una celebración alegre a una decepción escéptica, no leeríamos entonces la historia de una derrota común? El punto crítico de inflexión entre ambos episodios podría estar en el clima de amenaza irreversible y de reproche desesperado que esbozaba una canción de 1984 titulada "77" y firmada por Loquillo y Trogloditas. "77" prestaba título al extended play titulado ${ }_{\dot{C}}$ Dónde estabas tú en el 77 ? . La matriz del estilo country and western se cruza en "77" con la rabia punk para desembocar en un grito que atraviesa la soledad del lugar de enunciación, sin ilusión de compañía, una ilusión que no puede ya devolverse, que arraiga en la pérdida, en una acusación interrogante: "si las calles ya no arden / ¿quién ha sido el culpable?".

\section{La mitificación de un agujero}

En realidad, la hegemonización de la nostalgia empezó pronto en el terreno de la música popular reciente, y de hecho es una operación inscrita en el programa operativo de la industria cultural como tal. J. R. Pardo, por ejemplo, en Historia del Pop Español(2005), documenta en el año 1985 un llamativo boom nostálgico cuya manifestación más puntual y superficial posiblemente fuera el lanzamiento de un grupo de repertorio especializado en revival como era La Década Prodigiosa. Así, ya en 1985 se puede observar hasta qué punto la memoria colectiva no va a poder nutrirse de lo realizado, de lo(s) hecho(s), ya que esa ilusión de cambio, al menos para las generaciones más jóvenes, se ha quedado por el camino. En ese punto lo no realizado no cuaja, no puede cuajar en forma alguna de memoria puesto que no ha llegado a ser realidad: lo vivido en los últimos setenta y primeros ochenta ha sido tanto una experiencia como un deseo, y la inercia del tiempo irá poniendo en claro que ese deseo no se ha agotado pero sí se han agotado los cauces de experiencia que hacían de ese deseo no solo el deseo de una imposibilidad. El desgaste invivible del proyecto utópico, del que se ha hablado en términos de mono del desencanto (Vilarós 1998), no desemboca solo en la pesadilla mortífera de las drogas duras sino que abre una especie de corriente subterránea en el inconsciente popular por la que circula con fuerza la sensación de que el tiempo vivido está dejando de ser un tiempo real, de que todo ha tenido la fugacidad de un sueño del que solo quedan ya brasas a la intemperie. Sabino Méndez, guitarra y compositor de Los Trogloditas, cruzó como tantos ese desierto de lo real, y ha dejado anotada la consistencia de ese vacío común en apuntes como éstos: "un ser humano abandonado de una idea de sentido o destino de sus actos se convierte en un zombi" (2000: 169). Esa "debilidad extrema", ese "sentimiento de contingencia absoluta" del que habla Méndez en Corre, rocker tiene que ver con la certeza de vivir dentro de un espacio vacío, de un espaciamiento del tiempo histórico, que de hecho es percibido bajo la forma libre de 
un nicho de aire, de un agujero: "un monumental agujero en el tiempo histórico de la transición nos benefició de una manera enormemente afortunada a todos los heterodoxos" (2000: 63).

Es necesario insistir, pues, en que el "síndrome de abstinencia" no se reduce sin más a una patología derivada de la adicción drogodependiente sino que el recurso a la droga puede estar siendo una forma (entre otras) de afrontar con vida el desconsuelo de una intemperie tan imprevista como irremediable. Para Méndez o para Vilarós, por volver al curso de los acontecimientos, el hiperdiscurso de la movida es el mejor síntoma del declive palpable a partir de 1987. Como dice metafóricamente Vilarós (1998: 35), "la poesía práctica de la movida es en el fondo un tratamiento de metadona". Y en ese clima, la nostalgia, en efecto, se presenta como un remedio tan prematuro como eficaz. La reacción nostálgica permitía (y permite) retener aunque sea en precario algunas instantáneas de un tiempo apasionante, cuyas marcas históricas básicas fueron su aceleración histórica y su carácter efímero. El período paradójico y polémico de la transición instaura la inminencia de un cambio sin embargo continuamente aplazado, inacabado, proyectado hacia un futuro que no existe, y es esa dosis de inexistencia la que va abriendo huecos en la continuidad de la experiencia y la memoria. Lo explica con acierto excepcional Gérard Imbert (1990: 2021):

Lo que así se salva del olvido, no es tanto la historia como su escritura. (...) Toda escritura remite fantasmagóricamente a su origen, a lo que origina, constituye estructura- su relato, a una forma -primitiva- de no-dicho. Es, en el inconsciente colectivo, el franquismo, el "Pére-sévère" (Lacan): el Padre-que-sigue-ahí, que nadie ha matado (simbólicamente hablando). Este origen, turbio, que es un obstáculo para la constitución de un nuevo universo simbólico, es a la vez un objeto perdido y, por consiguiente, de nostalgia (la instancia paterna) pero también de abominación (sujeción, dependencia); es asimismo un objeto no cumplido (la ruptura) que remite a una muerte no consumada.

En otras palabras, la condición incumplida de la ruptura la hace pervivir, perseverar como deseo de muerte, como pulso voraz, destructivo, no tanto en la realidad como en el deseo de realidad que la transición activa en buena parte de la juventud española. Claro que ese pulso no puede entonces sino ser la amenaza fantasmagórica, silenciosa, invisible, de lo que puede terminar por romper (con) la vida. Ésa sería la amenaza inconsciente que la nostalgia promete exorcizar -aunque sea al precio de una cancelación de la memoria.

El principal resorte nostálgico puesto en marcha por la opinión pública y la cultura común post-transición ha sido el antiguo mito de la Edad de Oro. Es ilustrativo que La Edad de Oro empezara siendo el nombre de un influyente formato musical de Televisión Española conducido por Paloma Chamorro entre 1983-1985, es decir, inmediatamente 
después de finalizado (lo que Méndez llama) el "lustro irrepetible" 1977-1982. En 1987 la casa discográfica Ariola, ya integrada en el grupo transnacional BMG, lanza un disco recopilatorio triple de título La Edad de Oro del Pop Español, contando con la participación de los grupos-insignia del período new wave: desde Kaka de Luxe hasta Radio Futura, pasando por Golpes Bajos, Aviador Dro, Los Toreros Muertos, La Mode, Alaska y Dinarama, Mamá, Los Secretos y otros muchos. La vocación de totalidad de este lanzamiento discográfico se recoge de nuevo en el libro colectivo posterior del mismo título editado por Luca Editorial en 1992. Con el tiempo, lejos de perder impulso, el cuño mítico, como corresponde a su propia naturaleza y función (Barthes, 1957), se ha expandido y naturalizado en lanzamientos múltiples más recientes como el DVD doble La Edad de Oro del Pop Español (60 artistas / canciones) recopilado por BMG/Dro East West en 2004, o como el pack DVD+CD La Edad de Oro del Pop Español (Concierto Sinfónico) (2006) producido por Sony-BMG en colaboración con la Orquesta Sinfónica de Radiotelevisión Española. O como, también en 2006, el lanzamiento masivo por parte de Sony del karaoke La Edad de Oro del Pop Español, programado para consola de videojuegos (SingStar-Play Station2) en la estela exitosa de la Famicom japonesa de Nintendo. El website de Playstation anunciaba la novedad en el mercado con el titular: "Aquellos maravillosos años: La nostalgia de la movida madrileña irrumpe en la Play2". Y la noticia prosigue: "30 temazos que intentan abarcar todos los años y estilos...".

El afán de totalidad del mito no es inocente. La definición del mythos en la etimología griega, como se sabe, alude al conocimiento y la expresión de una realidad que excede los límites de la experiencia y de la razón. Esa expresión es siempre narración, relato, construcción, y es además narración ambivalente por principio: señala un tiempo primordial, original, en el pasado, que en esa medida es semilla de un presente que se celebra; al tiempo que sintomatiza una historicidad en crisis. La realidad histórica, como explicara Barthes (1957: 252 y ss.), es despolitizada e inmovilizada por el relato mítico, cuya función principal es la de naturalizar la vida social bajo la forma de una realidad no social, no histórica. La frase de Barthes no deja de ser provocativa: "estadísticamente, el mito es de derechas" (1957: 257). No obstante, igual que dos negaciones dan una afirmación, la recurrencia de lo nuevamente fijado por el mito puede poner en evidencia su carácter de constructo, de artificio arbitrario e interesado. Esa condición de constructo ideológico del mito es de hecho lo primero que el mito necesita negar, mediante una hipóstasis de lo sobrenatural e incluso de lo sagrado, de lo que por definición no se toca: el suceso mitificado esplende como ejemplar al tiempo que, por esa misma razón, no se discute, se sustrae a la crítica y al cambio. 
En concreto, el mito de la Edad de Oro viene de lejos. Ya Virgilio, en la Égloga IV, había convertido la Edad de Oro en visión profética, y desde ahí se convierte en un continuo cruce de caminos:

En ese instante confluyen la Edad de Oro y la utopía político-social. Si aquél se proyectaba hacia un pasado inmemorial, ésta modela un espacio ausente y un futuro ignorado (Guillén, 2005: 262).

Ya a finales del siglo IV d. C. Prudencio recupera el mito áureo virgiliano en Contra Símaco (I) para legitimar las conquistas de Roma y ensalzar la figura del emperador Teodosio como médico de almas que, al prohibir el culto pagano, consiguió espiritualizar su imperio y combatir la enfermedad de la parálisis secular. En un principio, sin embargo, el mito de la Edad de Oro se da en Virgilio como una mitificación todavía no consciente ni madura en cuanto a sus potencialidades ideológicas y políticas: remite de forma germinal al ensueño de un tiempo, como dice Ovidio en el libro primero de sus Metamorfosis, "sin ley ni rey". La ilusión ácrata del mito, impulsada no por su carácter libertario sino por su condición mítica misma, tendería a lo largo de la historia a figurar o fijar un pasado ideal como medio de justificación de un presente en crisis. En la línea de las palabras de Claudio Guillén, se puede decir que la Edad de Oro idealiza el pasado como forma eficaz de cubrir la falta de un presente, de un presente que falta como proyección histórica, y que solo contempla el agujero de un "futuro ignorado", sin aliento, como ya anticipara el conocido lema punk: NO FUTURE. Dicho de otra forma, el mito de la Edad de Oro puede funcionar como mecanismo de defensa post-autoritario pero también post-libertario, como antídoto amable contra la desesperación punky -por otra parte, tan importante para entender la dimensión transgresora de la música popular española en la transición en casos como Parálisis Permanente, Los Nikis, Polansky y el Ardor, Las Vulpess, los primeros Siniestro Total, o también lateralmente en Golpes Bajos, Alaska y Pegamoides, Los Burros o Trogloditas, entre otros.

Desde esta perspectiva, la imposibilidad de la memoria juega a favor del borrado de la historia que confirma el mito. Y a la inversa: ambos elementos se refuerzan mutuamente, de una forma efectiva pero que no tiene por qué ser deliberada. En ese cruce de vectores estratégicos sería oportuno observar más despacio qué hacen con la música popular el mercado y el estado.

Mediados los años ochenta, la evolución del negocio del disco era ya ilustrativa en este sentido. La industria del rock nace a partir del esfuerzo de grandes compañías fundamentalmente norteamericanas, como CBS, WEA y RCA. En el último tercio del siglo XX solo dos megaempresas europeas, Philips y EMI, participan en el reparto de la gran tarta comercial que representa el auge de la nueva música popular. Con el avance de la década de 1980 la economía internacional pone las bases de una globalización de los 
mercados que implica un cierto reequilibrio de poder a nivel geoestratégico, a pesar de que el dominio estadounidense seguirá siendo incontestable, y sobre todo, implica la globalización una nueva lógica del mapa productivo mundial que exige nuevos pactos entre agentes transnacionales y agentes locales, de forma que el flujo del capital (y también del capital simbólico y cultural) no se colapse y pueda ser redinamizado en el nuevo marco de transacción global. Como explicaba con optimismo J. M M $^{\text {a }}$ Cámara (1987: 594), vicepresidente y director general de BMG-Ariola España:

Las grandes compañías multinacionales, actuando simultáneamente en muchos países distintos, ya no funcionan en una sola dirección. Cada unidad, cada país, procura desarrollar el talento local e incorporarlo al flujo general de información a través de su red internacional. La aldea global aparece posible, y la marcha hacia el cerebro global, inevitable. En el grado en que cada país, cada comunidad creadora, mantenga el equilibrio entre lo que aporta y lo que recibe de la corriente global está la clave de la autosatisfacción o la frustración.

Solo cinco años después del diagnóstico de Cámara era ya relativamente fácil encontrar apreciaciones no tan eufóricas sobre la industria musical española en los 80 , como ocurre en el artículo "La industria del disco: diez años de reconversión", del periodista D. Vico (1992: 74-75):

Las compañías renovaron sus estructuras, redujeron su personal y rejuvenecieron sus departamentos artísticos. Y se produjeron algunos cambios en la capital. CBS se reagrupaba con Epic, al igual que Fonogram y Polydor se reconvertían en Polygram. Posteriormente, EMI e Hispavox se fusionarían, al igual que, siguiendo consignas exteriores, lo harían RCA -que había comprado Columbia- y Arbola en el grupo BMG. Por el contrario, compañías veteranas como Belter o Movieplay desaparecían mientras se instalaban en España Virgin y WEA.

Solo el cuidado del producto nacional, siguiendo a Vico, explica la resurrección de ventas en la segunda mitad de los ochenta. En 1993, el informe sobre el estado del mercado musical preparado por el Ministerio de Cultura manifestaría que

la progresiva concentración y transnacionalización empresarial que tuvo lugar durante la década de los ochenta llevó a la desaparición de la mayoría de las empresas de tipo medio de capital español, como Hispavox, Columbia, Belter o EDIGSA. A comienzos de los años noventa, la única empresa importante de capital español es DRO/GASA/Twins, con una cuota de mercado en 1989 de aproximadamente un 2,4\% del total. (VVAA, 1993: 104)

Esto significa que la industria musical en España está respondiendo a las pautas estructurales experimentadas por la industria discográfica a escala internacional, y que se 
habían iniciado en el mundo anglosajón durante la década anterior. Esa transformación había sido descrita en términos tendenciales como una conjugación de oligopolización, conservadurismo y estandarización. A España llega WEA en 1981 y Virgin en 1983, EDIGSA cierra en 1983, aunque sus fondos pasan a ser explotados por PDI, en 1984 tiene que cerrar Belter, Odeón pasa a formar parte de EMI, que absorbe a Hispavox, Columbia es adquirida por RCA... se trata de un "contexto convulso" (Fouce, 2002: 106) que, en un primer momento, pudo promover la proliferación de casas independientes (Dro, Tres Cipreses, GASA, Lollipop, Twins, Nuevos Medios...) pero que, dada la tendencia estructural de la industria, desemboca en la presión estandarizadora y la minimización de riesgos propia de los últimos ochenta y primeros noventa. La crisis de crecimiento global en las industrias culturales se resuelve así en un proceso de re-concentración oligopólica que, no obstante, requiere de una atención intensiva hacia la producción local integrada.

De este reajuste industrial se derivan, en suma, dos factores que influyen directamente en la cultura musical española post-80: uno, "la falta de diversidad y de inteligencia" (Alcanda, 1991) en las programaciones radiofónicas y mediáticas en sentido amplio; y dos, simultáneamente, una parálisis creativa condicionada por el clima asfixiante que el contexto productivo y mediático impone. El momento explosivo de principios de los ochenta quedaba así neutralizado y canalizado a gran escala. Atrás quedaba la sensación descrita por D. Silva en 1984:

Los sellos independientes, planteándose una dinámica autogestionada y autosuficiente, han convertido en empresarios a jóvenes amantes de la música, convirtiendo así a los empresarios de las discográficas en viejos arterioescleróticos que no tienen ni idea de música (1984: 13).

Las inseguridades empresariales del período 1977-1984 habían abierto un espacio propositivo, conflictivo, que la reconfiguración supraestatal del mercado discográfico terminaría por neutralizar. Ya en 1987, como señala Pardo (2005), la crisis económica internacional exige reajustes en el circuito de la cultura masiva que van asociados a una palpable decadencia musical. Por eso, el aparatoso lanzamiento que en 1987 hace el diario El País de la colección Historia del Rock es algo más, o algo menos, que un mero gesto celebratorio: puede, de hecho, interpretarse como el momento en que un cadáver comienza a prepararse para ser embalsamado. No es extraño que el disco Los alegres 80, editado también por El País en su colección de cedés Un país de música 2 (2002), reconociera en su solapa interior que en esa década se había logrado "la normalización del pop en castellano". La sanción normalizadora actuaba ahí, como en otros discursos y prácticas culturales y políticos, en la línea de lo que Foucault llamaría "los medios del buen encauzamiento" (Foucault, 1998). Las canciones populares de la transición podían ya ser 
vistas, y de hecho así empezaba a suceder en los últimos ochenta, como la música de un país, como la banda sonora de un estado por fin democrático y moderno.

En conclusión, de lo anterior se desprende que la españolización de la música popular en la transición responde (de forma quizá no exclusiva pero sí indudable) a la confluencia de dos líneas de interés: un interés de mercado, que requiere de una insistencia estratégica en las identidades locales como precondición para un reequilibro industrial global; un interés de estado, que sufre una previsible ansiedad por renovar su cohesión política e identitaria tras el final de una época histórica y el comienzo de una nueva. Por esta vía, la mitificación del rock español, incluso la construcción de esta etiqueta promocional, se acelera paradójicamente (o lógicamente, si se atiende al carácter compensatorio de todo mito) cuando el declive creativo y crítico de esa música parece incontestable.

Y puede que sea justamente la condición musical de esa serie de prácticas culturales (pop-rock español, nueva ola, música de la movida...) lo que facilita en comparación (en contraste por ejemplo con el cine, el cómic o la literatura) que sean sometidas a un proceso de mitificación acelerada. El mito acude a resituar el no-lugar que la música como práctica social abre en la cultura común, a encauzarlo hacia un modo de circulación funcional al puritanismo heredado por la cultura oficial en la modernidad capitalista (Gilbert y Pearson 2003: 267 y ss.). La invisibilidad del vigor popular en el momento de su emergencia se traduce, así, a una hipervisibilidad masiva, calmante, inofensiva. En la medida en que los cambios musicales y los cambios sociales caminan juntos (Small, 2006), el neoconservadurismo de los años noventa exige una reconversión acrítica de prácticas musicales que podrían tener que ver con efectos no tan tranquilizadores. Entre esos efectos (y afectos) ocupa un lugar de privilegio la movilización corporal a través del baile, que ya era un motivo de inquietud política incluso para Platón. El éxito popular y comercial de Alaska y Pegamoides con la canción "Bailando" (1982) denota el poder de este resorte ambivalente y decisivo: el baile, como forma libertaria de goce y de encuentro, como experiencia sexual y como arte del débil (De Certeau), es de hecho una marca definitoria de las nuevas músicas en comparación con la música para la escucha que representaba el estilo de los cantautores en el franquismo tardío. "Bailando" tenía que ser no solo una canción: tenía que ser un himno. Su momento desenfadado y nä̈e distingue esta pieza del tratamiento oblicuo e irónico que reciben otras piezas en esa onda de los primeros ochenta, como en el reggae titulado "Divina (Los bailes de Marte)" o en la deliciosa "Dance Vd", ambas de Radio Futura, o del tratamiento ácido y destructivo que es llevado al extremo en "Branquias bajo el agua" de Derribos Arias. Asimismo, el enfoque abiertamente poppy de "Bailando", no asimilable sin más a otras canciones menos amables de Alaska y Pegamoides ("Odio", "Quiero Salir", "Vértigo", "Redrum"...), la convierte casi sin querer en un 
precedente del importante (y otra vez políticamente ilustrativo) éxito de Olé Olé en 1986: "Bailando sin salir de casa".

\section{La destrucción de la forma: una cuestión de estado}

La consideración de la música como práctica social abre la caja de los truenos. El prejuicio tradicionalista y elitista que ve en la música un ámbito estético autónomo, purificado de toda contaminación mundana, se viene revisando críticamente desde la antropología musical, la etnomusicología y la crítica de la cultura. Esta reformulación crítica de los vínculos entre música, sociedad y poder puede estar todavía en un estadio de desarrollo inicial, tal vez. Pero eso no vuelve la cuestión menos relevante. Y esta relevancia explicativa se hace aún más necesaria y propicia en el caso de la música popular, donde los nexos de la música con la vida común están a la vista en sus más distintos órdenes, desde los mass-media hasta la cultura callejera, desde el ruido o el sexo en el espacio de la fiesta hasta las leyes de la mercadotecnia y la concepción del estilo en manos de la juventud, desde las más nuevas manifestaciones artísticas hasta la condición mutante de las más diversas sub- y contraculturas, y así sucesivamente...

Un pasaje de Jacques Attali (1977: 13) resume el punto de partida necesario para avanzar en este camino crítico:

La música es en un sentido metáfora creíble de lo real. No es ni una actividad autónoma ni una implicación automática de la infraestructura económica. Es a la vez huella y anuncio, pues el cambio se inscribe en el ruido con más rapidez de lo que tarda en aparecer la sociedad que él anuncia.

Claro está, lo que Attali llama "el cambio" puede ser aplicado de modo fructífero a la dinámica del poder social e institucional en la época de la transición española de la dictadura franquista a la democracia de masas. Attali explica con detalle cómo la música en la historia puede ser tanto una herramienta de control como un peligro para el poder establecido: "la música es como la multitud, a la vez amenazadora y fuente necesaria de legitimidad, riesgo que todo poder debe correr tratando de canalizarla" (1977: 29). En este sentido, la fuerza transversal de la música implica tanto la inminencia del análisis cultural y político en sentido amplio como, a la vez, "una llamada a la indisciplina teórica" (Attali 1977: 13) que sea coherente con el funcionamiento descentrado y asistemático de las prácticas musicales populares.

Precisamente la música popular de raíz urbana y contemporánea es un lugar idóneo, aunque no el único, para entender cómo la ilusión de armonía clásica se torna en conflicto y en proliferación de ruido, en perturbación corporal y social. En los términos de Attali (1977:54): 
El ruido fue siempre sentido como destrucción, desorden, suciedad, polución, agresión contra el código que estructura los mensajes. Remite, pues, en todas las culturas, a la idea de arma, de blasfemia, de plaga. (...) En su realidad biológica, el ruido es un medio para hacer daño.

No resulta extraño, pues, que el ruido sea percibido como una "amenaza mortal" por los regímenes autoritarios, entre los que se encuentra no solo el comunismo de estado o el fascismo clásico sino también el fascismo postmoderno, de mercado, o fascismo de baja intensidad con que se topa el modelo global de democracia (neo)liberal hoy en día. En el caso de la transición española a la democracia, el fascismo está demasiado presente, inercialmente vivo, como para que desaparezca de la noche a la mañana, y el capitalismo es demasiado pujante como para disimular su protagonismo en el cambio colectivo. Fascismo y capitalismo se cruzan así con tácticas libertarias múltiples, a menudo preconscientes, de resistencia y subversión, que encuentran en la cultura popular una arena nueva para la lucha y el conflicto.

El caso español, tenido por ejemplar en importantes sectores de la opinión pública y la diplomacia internacional, presenta como singularidad no solo la combinación de fascismo y capitalismo, que estaba ya sin ir más lejos en el contexto del nazismo alemán, sino el paso hacia una peculiar articulación de capitalismo, democracia y monarquía. Un ensayo poco citado pero útil, en este punto, por su forma de articular fascismo y capitalismo, y de dirimir el juego diferencial y relacional entre democracia y monarquía, es el texto del joven Georges Bataille El estado y el problema del fascismo (1993), original de 1933. Siguiendo a Bataille, el Estado capitalista presenta la homogeneización como normalización, de forma que encuentra ahí un espacio de consenso entre autoridad (despótica) y adaptación (democrática). Toda heterogeneidad o alteridad es percibida entonces como resto, como desperdicio improductivo. En el Estado capitalista el fascismo encontraría un ámbito óptimo de condensación religiosa-militar e interclasista del poder como poder masivo. Para Bataille, esto conlleva que la naturalización/institucionalización de la normalidad (democrática) convierta en "forma imperativa" incluso la libertad y el movimiento (1993: 41). La democracia se habilita de este modo a sí misma para bloquear el cambio social radical en la medida en que este cambio ha de ser regulado por un marco institucional e ideológico represivo. Evidentemente, esta dinámica es una dinámica inestable y abierta al conflicto. Lo curioso es que ese conflicto, que podría incluso intensificarse hasta interrumpir la inercia institucional o sistémica, quedaría amortiguado por la instalación de un eje monárquico en el interior del marco democrático, ya que lo característico de la sociedad monárquica sería que

la necesidad del cambio solo está representada interiormente por una minoría consciente: el conjunto de los elementos homogéneos y el principio inmediato 
de la homogeneidad permanecen ligados al mantenimiento de las formas jurídicas y de los marcos administrativos existentes y garantizados por la autoridad del rey; recíprocamente, la autoridad del rey se confunde con el mantenimiento de estas formas y marcos (Bataille, 1993: 40).

Desde esta perspectiva, el imperativo homogeneizador o normalizador se convierte en el garante de estabilidad en tiempos de cambio para un sistema político fascista que necesita ser democrático y capitalista, y que encuentra en la monarquía un marco de legitimidad lo suficientemente firme y seguro. Pero, con todo, cipuede la normalización funcionar como un mecanismo de relojería? ¿No es cierto, como dice Attali (1977: 67), que "una red puede ser destruida por ruidos que la agraden y la transforman si los códigos en vigor no pueden normalizar y reprimir esos ruidos"? ¿Cómo actúa en esa tesitura el ruido (de la música popular) consciente de participar en una situación de conflicto y de cambio social? ¿Hacia qué posiciones se orienta por ejemplo la tendencia al bricolaje y la inclusividad popular del rock (Berio, 1971: 58) en condiciones de normalización macrosocial? La respuesta, sin duda, debería ser compleja, heteromórfica y heterológica. En lo que sigue presentaré solo algunas pistas para que esas respuestas puedan ir siendo posibles con paciencia.

Para abordar la capacidad corrosiva de determinados discursos y prácticas musicales podría ser de ayuda una noción benjaminiana como la destrucción de la forma. Para Benjamin, el concepto de ironía en Schlegel está vinculado a la "exteriorización de una oposición siempre viva contra las ideas dominantes" (Benjamin, 1995: 21). Este gesto de resistencia y oposición lo realizaría una ironía que no se quede en el enunciado sino que afecte al lugar de la enunciación, minando la posibilidad de unidad en la forma. En un sentido cercano a la concepción del drama épico en Bertolt Brecht, la ironización de la forma produciría una distancia en el espacio de la mirada o de la escucha que impediría la absolutización ilusa de la ilusión representativa. Benjamin dialoga así con Schlegel:

"Debemos elevarnos sobre nuestro amor propio y ser capaces de aniquilar en el pensamiento aquello que adoramos, si es que no nos falta... el sentido para el infinito". En estas manifestaciones se ha expresado Schlegel claramente sobre el elemento destructor en la crítica, sobre su acción disgregadora de la forma artística. Así pues, muy lejos de representar una subjetiva veleidad del autor, esta destrucción de la forma es la tarea de la instancia objetiva en el arte, la tarea de la crítica (Benjamin, 1995: 125).

La destrucción de la forma se apoyaría en un efecto de "irritación" (Benjamin, 1995: 124) que socavaría la transparencia clásica y abismaría la obra, la forma musical en este caso, en una experiencia de extinción que fuera a la vez, como diría Adorno, una huella de 
la extinción de la experiencia. En este punto la escritura poética se vuelve necesariamente autorreflexiva.

Mi hipótesis es que esta autorreflexividad es la que subyace a la producción de un grupo musical que se bautiza a sí mismo como Derribos Arias. Las grabaciones de Derribos Arias, especialmente las realizadas entre 1982 y 1983 y recogidas en Branquias bajo el agua y en el elepé En la guía, en el listín, son huellas de una deriva delirante y transgresora. Esta deriva se asume como interrupción del orden del discurso, como colapso agonizante en momentos de intensidad límite como "A flúor", "Lo que hay" o "Introducción". Pero, más allá de esos infartos repentinos, el sonido y el ruido de Derribos Arias se despliega en un collage convulso, dislocado, que desde el principio destruye la supuesta autoridad logofonocéntrica (Derrida) de la voz solista mediante cadencias inexpresivas, anticanónicas, con frecuencia ilegibles. Las letras, a su vez, afrontan desde ese ángulo corrosivo temáticas políticas de actualidad, como en "Europa", en "Misiles hacia Cuba" o en "Dios salve al Lehendakari". La destrucción de la forma, en Derribos Arias, enseña su filo inquietante, autoconsciente, en sus impugnaciones irónicas de la cosmovisión fascista, mediante referencias discontinuas al nazismo y al holocausto ("Aprenda alemán en 7 días", "Lili Marlen", "Crematorio"...).

Por lo demás, si el rastreo de ruido destructivo en la banda sonora de la transición española empezara por los títulos de las canciones, seguramente ocuparía un lugar destacado "Mensajeros de la destrucción" de Barón Rojo, incluida en el disco en directo Al rojo vivo (1984). Como sucede con la matriz del estilo heavy metal, la transgresión en Barón Rojo radica en la nueva crudeza de lo que se dice: "hablan los jerarcas de negociación: / farsantes sin pudor / que siembran el terror". El ataque frontal a la clase política se plantea en términos de una dialéctica ellos/nosotros común a la retórica de denuncia del rock duro, no necesariamente inmerso en la parafernalia heavy, como fuera el caso de Leño, cuya canción "Corre, corre" (tema central del disco Corre, corre de 1982) proclamaba que "sabemos lo que quieren y aunque no nos convenció / estamos en el juego y somos su preocupación". En la misma dirección, y en el mismo disco de Leño, se incluía la canción "Que tire la toalla". El rock barriobajero de Leño y su cantante Rosendo Mercado, que se presentaba en los conciertos de 1982 vestido con un mono blanco sin mangas, trabaja con un efecto de camaradería, de mutualidad no reducible al parámetro del comportamiento fan, y apuesta por una desnudez sonora y verbal que le valió un seguimiento comparativamente mayoritario en momentos en que "la calle volvía a ser de la gente" (Lechado, 2005: 37). El caso del heavy de Barón Rojo o de Obús comparte con el rock duro esta demostración de contrapoder subalterno, cohesionado más allá de los límites de la tribu. Sin embargo, el rock heavy extrema al máximo una pauta ya activa en el rock duro: la necesidad del grito, de la amplificación de las guitarras, de la percusión violenta... 
En una palabra, se puede decir que la política del heavy no es tanto una táctica destructiva (los mensajeros de la destrucción en la canción de Barón Rojo son "ellos", los otros) como una transgresión enunciativa basada en la necesidad del hacerse-oír.

En otra poética musical está el género tecno, tal como era concebido por ejemplo por El Aviador Dro y sus Obreros Especializados, cuyo primer disco de larga duración (Alas sobre el mundo, 1982) se abría estratégicamente con el track "Brigada de demolición". La vestimenta proletaria de Rosendo en Leño y el afán demoledor de Poch en Derribos Arias convergen en la ficción futurista y contrautópica de Aviador Dro: "los obreros cantan sobre el ruido / la ciudad de las máquinas despierta // brigada de demolición / derribar para construir...". Lejos de producir un efecto automatizador o meramente mecánico, Aviador Dro consigue poner la tecnología al servicio de un erotismo bailable (como especialmente sucede en "Ondina" o en "Cita en el asteroide"). La destrucción de la forma, en el caso de la música tecno iniciada por formaciones como los alemanes Kraftwerk o los norteamericanos Devo, pone en escena un universo postindustrial en clave de resaca colectiva, donde el componente maquínico disuelve el aura de naturalidad y autoridad propias del folk, o de autenticidad y originalidad propias del rock. La producción sonora de Aviador Dro retoma la conexión entre tecnología, cuerpo y baile en la clave blasfematoria del cyborg, tal como lo ha expuesto D. Haraway:

El cyborg elude el paso de la unidad original, de identificación con la naturaleza en el sentido occidental. Se trata de una promesa ilegítima que puede conducir a la subversión de su teleología en forma de guerra de las galaxias (Haraway, 1995: 255).

La tecnificación sonora avanzada (uso de sintetizadores, cajas de ritmos, programadores...) se infiltra de forma capilar en otros grupos del momento, y llega a convertirse por momentos en una nueva doxa masiva gracias al éxito de grupos como Azul y Negro. Sin embargo, no siempre el componente tecno se asocia a una visión eufórica o aséptica sino que recala en connivencias con códigos más amargos, como fue el caso de la combinación de sonido tecno y vocalidad post-punk en Golpes Bajos. El grupo de Germán Coppini (exSiniestro Total) y Teo Cardalda, pese a su breve trayectoria, fue único, quizá junto con las secuelas de Parálisis Permanente, en delimitar tonalidades catabáticas y ambientes de miedo, enfermedad y malestar sin descanso, en la estela del teatro y el arte de la vanguardia expresionista. Con Golpes Bajos, la destrucción de la forma se da en virtud de una voz entendida como lamento, cuyo fraseo desborda los límites prefijados por una melodía elemental. O bien se canaliza mediante desajustes no ya entre la voz y la melodía ("Ayes") sino entre el tema y el modelo rítmico (como en la samba alocada "La reclusa" o en la salsa esquizoide "Colecciono moscas"). O se explicita como destrucción de la infancia ("Hansel y Gretel"), de los vínculos interpersonales ("Desconocido") o de la beatitud 
impuesta y represiva ("La virgen loca")... La locura y la infancia, el abandono y el aislamiento forman parte de una misma poética del rechazo en Golpes Bajos, que alcanza un instante agónico pero de nuevo bailable (como si se tratara de un baile angustiado y absurdo) en "Fiesta de los maniquíes", incluido en A Santa Compaña (1984), cuya percepción de lo social como vacío sintonizó con una experiencia de la subjetividad cada vez más extendida, más desértica, y menos reconocida por las instancias eufemísticas de la política institucional.

Pero si en algún lugar del paisaje acústico se dio sin remedio la fatídica combinación entre música de baile y el trastorno de la autenticidad (y sus significados adyacentes: originalidad, naturalidad, identidad, realidad...) fue en la forma de entender la música de Tino Casal. Con la colaboración experimental en el estudio de Julián Ruiz, Casal se lanza a recorrer un cruce inédito en la tradición española entre exploración tecnológica (recurso al sampler, secuenciador de ritmos, sintetización de sonidos y voz, vocoder...) y estilo glam aprendido en Bolan, Bowie, y The Human League. El resultado es una experiencia de inestabilidad y tensión sonora que se comparte con otros proyectos asociados por entonces a la investigación tecno y la cold wave (como el caso de Claustrofobia), pero que incorpora además un suplemento liminar mediante el forzamiento melódico y una voz amenazada por su eco, precipitada en los aledaños de una excitación que se asume como impostura.

No es raro que Casal abriera su repertorio en la gira de 1983 con "Legal, ilegal". Esta canción consigue ser un emblema de la crisis de la Realidad y del Significado promovida por la digitalización de la música popular (Goodwin, 1990), y lo consigue no solo por la sofisticación de su aparato técnico o reproductivo, o por la confianza erótica, deseante, en una línea de bajo marcada por el funky y la necesidad corporal del baile, sino por cómo esa crisis es traducida a sintaxis verbal mediante un juego de oposiciones convocadas en torno a una elipsis, a un agujero de sentido. Como el estribillo insiste en recordarnos: "Es legal, es ilegal. / Es solo un truco y nada más. / Es legal, es ilegal. / Tan solo tú lo entenderás". "Legal, ilegal" procura así una suerte de deconstrucción por seducción de esa clave ideológica del "razonable realismo" (García San Miguel, 1981: 17) que se estaba convirtiendo en la piedra angular para la construcción a gran escala de un nuevo consenso público naturalizado como democrático. La línea divisoria entre lo normal y lo anormal, entre lo real y lo irreal, entre lo posible y lo imposible... queda cuestionada, rebasada por el juego rítmico que nos hace saltar de una orilla a otra, como en un desliz por la barra (/) que separaría lo legal de lo ilegal -con todas las resonancias que este juego conjura en el terreno de las prácticas sexuales, de la droga, de la política profesional, del mundo de los negocios, etc. Como aclara Imbert (1990: 42):

Los grandes debates de la transición, aparte de los que afectan a los cambios propiamente institucionales, obedecen a un doble impulso: una necesidad de 
socializar el hacer de los sujetos (adecuación de las prácticas -más o menos salvajes- a unas conductas -más o menos normalizadas; y una necesidad de ratificar, de formalizar ese hacer, es decir, de sancionarlo de acuerdo con la ley; en términos jurídicos: prohibir / despenalizar / legalizar:

Aunque no siempre se ha pensado en esto con detenimiento, la música de Casal nos recuerda que, en aquel entorno de nuevas regulaciones disciplinarias, el cuerpo está en el centro de esas batallas físicas y culturales, y que en la posibilidad de (re)mover el cuerpo de otra forma hay algo más en juego que un estilo, una imagen o una forma de gobierno. El estudio de estas y otras manifestaciones de la música popular podría, en suma, contribuir a clarificar cómo la comprensión de un tiempo histórico, sea pasado o presente, no depende solo de "los cambios propiamente institucionales", y cómo incluso estos cambios en la cultura oficial pueden estar siendo reformulados y desviados por la cultura común hacia otro sitio. 


\section{Bibliografía citada}

Alcanda, Santiago (1991). "Los nuevos medios musicales". VVAA, Un año de rock '91. Madrid: Luca Editorial.

Attali, Jacques (1977). Ruidos (Ensayo sobre la economía política de la música). Valencia: Ruedo Ibérico.

Barthes, Roland (1957). Mythologies. Paris: Éditions du Seuil.

Barthes, Roland (1993). Fragmentos de un discurso amoroso. Madrid: Siglo XXI.

Bataille, Georges (1993). El estado y el problema del fascismo. Valencia: Pre-Textos / Universidad de Murcia.

Bauman, Zygmunt (2001). La sociedad individualizada. Madrid: Cátedra.

Benjamin, Walter (1990). Discursos interrumpidos I. Madrid: Taurus.

Benjamin, Walter (1995). El concepto de crítica de arte en el romanticismo alemán. Barcelona: Península.

Berio, Luciano. "Commentaires au rock". Musique en Jeu 2 (1971): 56-65.

Bradby, Barbara (1990). "Do-Talk and Don't Talk (The Division of the Subject in GirlGroup Music)". Frith, S. y Goodwin, A. (eds.) On Record (Rock, Pop, \& The Written Word). London: Routledge: 341-368.

Cámara, José M ${ }^{\mathrm{a}}$ (1987). "Las claves de la música grabada". VVAA Historia del Rock. Madrid: El País: 593-594.

Feuer, Jane (1992). El musical de Hollywood. Madrid: Verdoux.

Foucault, Michel (1998). Vigilar y castigar. Madrid: Siglo XXI.

Fouce, Héctor (2002). El futuro ya está aquí: Música pop y cambio cultural en España 1978-1985. Madrid: Universidad Complutense.

García San Miguel, Luis (1981). Teoría de la transición (Un análisis del Modelo Español 1973-1978). Madrid: Editora Nacional.

Gilbert, Jeremy y Pearson, Ewan (2003). Cultura y políticas de la música dance. Barcelona: Paidós.

Goodwin, Andrew (1990). "Simple and Hold (Pop Music in the Digital Age of Reproduction)". Frith, S. / Goodwin, A. (eds.) On Record (Rock, Pop, \& The Written Word). London: Routledge: 258-273.

Guillén, Claudio (2005). Entre lo uno y lo diverso. Barcelona: Tusquets.

Haraway, Donna (1995). Ciencia, cyborgs y mujeres (La reinvención de la naturaleza). Madrid: Cátedra. 
Imbert, Gerard (1990). Los discursos del cambio (Imágenes e imaginarios sociales en la España de la Transición 1976-1982). Madrid: Akal.

Lechado, José Manuel (2005). La movida (Una crónica de los 80). Madrid: Algaba.

Méndez, Sabino (2000). Corre, rocker (Crónica personal de los 80). Madrid: Espasa-Calpe.

Pardo, José Ramón (2005). Historia del pop español. Madrid: Rama Lama.

Silva, Diego (1984). El pop español. Barcelona: Teorema.

Small, Christopher (2006). Música, sociedad, educación. Madrid: Alianza.

Vico, Darío (1992). "La industria del disco: diez años de reconversión". VVAA La Edad de Oro del Pop Español. Madrid: Luca Editorial: 74-75.

Vilarós, Teresa M. (1998). El mono del desencanto: Una crítica cultural de la transición española (1973-1993). Madrid: Siglo XXI.

VVAA (1993). La cultura en España y su integración en Europa. Madrid: Ministerio de Cultura. 